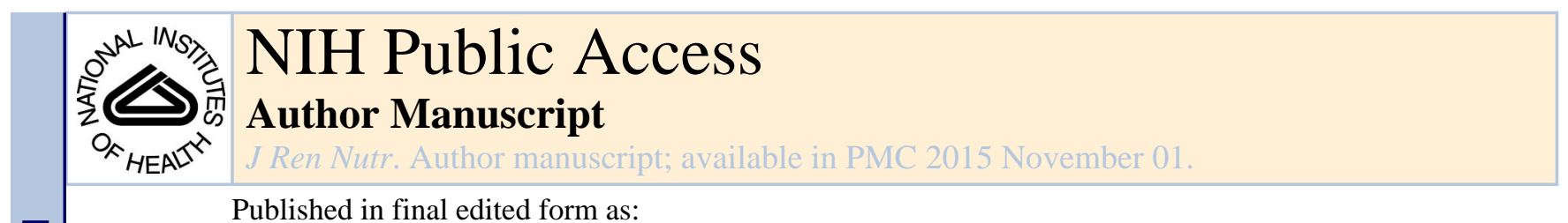

Published in final edited form as:

J Ren Nutr. 2014 November ; 24(6): e51-e53. doi:10.1053/j.jrn.2014.07.012.

\title{
Exercise for Chronic Kidney Disease
}

Danielle L. Kirkman ${ }^{1}$, Shannon Lennon-Edwards ${ }^{1,2}$, and David G. Edwards ${ }^{1}$

${ }^{1}$ Department of Kinesiology and Applied Physiology, University of Delaware

2 Department of Behavioral Health and Nutrition, University of Delaware

\section{Keywords}

Exercise; Chronic Renal Insufficiency; Renal Dialysis; Peritoneal Dialysis; Kidney

Transplantation; Chronic Kidney Disease

Due to fatigue and muscle weakness, patients with chronic kidney disease (CKD) have low levels of physical activity ${ }^{1}$. The decline in physical capacity in this patient cohort is noteworthy as it is associated with deconditioning and muscle wasting, declining kidney function and an increased risk of comorbidities such as cardiovascular disease ${ }^{2}$. Thus a downward spiral between disease, disuse and deconditioning exists leading to a reduced quality of life, increased hospitalization rates and mortality.

Increasing physical activity is therefore an essential aspect of disease prevention and management in CKD patients. Current NKF KDOQI guidelines for clinical practice suggest that encouraging participation in physical activity should be part of the routine care plan ${ }^{3}$.

These guidelines recommend "cardiovascular exercise at a moderate intensity for 30 minutes on most, if not all, days per week and that patients who are not currently physically active or are severely deconditioned should start at very low levels and durations, and gradually progress to this recommended level" 3 .

Over three decades of research has revealed a myriad of health benefits as a result of regular exercise in patients with CKD. These benefits include increased physical fitness and muscle strength; prevention of muscle wasting; improvement in cardiovascular health; improved nutritional parameters and a reduction of chronic inflammation ${ }^{4}$. In addition to physiological benefits, exercise improves health related quality of life and has shown psychological benefits such as decreases in anxiety, stress and depression in this patient population ${ }^{5}$.

Despite current guidelines and favorable evidence, exercise is still not prescribed as part of routine care for CKD patients. The multidisciplinary nephrology team is an integral part of

(C) 2014 by the National Kidney Foundation, Inc. All rights reserved.

Corresponding Author: David G. Edwards Department Kinesiology and Applied Physiology 201Q Health Sciences Complex Newark, DE 19713 (302)831-3363 dge@udel.edu.

Publisher's Disclaimer: This is a PDF file of an unedited manuscript that has been accepted for publication. As a service to our customers we are providing this early version of the manuscript. The manuscript will undergo copyediting, typesetting, and review of the resulting proof before it is published in its final citable form. Please note that during the production process errors may be discovered which could affect the content, and all legal disclaimers that apply to the journal pertain. 
encouraging and integrating physical activity and regular exercise into clinical practice. The nephrology dietitian is especially key since this individual can easily combine counseling for healthy eating habits with the need for exercise. The information provided is aimed to promote physical activity counseling and empower health providers to prescribe exercise a routine part of care for CKD patients.

\section{Supplementary Material}

Refer to Web version on PubMed Central for supplementary material.

\section{References}

1. Johansen KL, Chertow GM, Ng AV, et al. Physical activity levels in patients on hemodialysis and healthy sedentary controls. Kidney Int. 2000; 57(6):2564-2570. [PubMed: 10844626]

2. Painter $P$, Roshanravan $B$. The association of physical activity and physical function with clinical outcomes in adults with chronic kidney disease. Curr Opin Nephrol Hypertens. 2013; 22(6):615623. [PubMed: 24100215]

3. Bolton K, Beddhu S, Campese V, et al. K/DOQI clinical practice guidelines for cardiovascular disease in dialysis patients. American Journal of Kidney Diseases. 2005; 45(4):S7-S153.

4. Heiwe S, Jacobson SH. Exercise training for adults with chronic kidney disease. Cochrane Database of Systematic Reviews. 2011; (10):CD003236. [PubMed: 21975737]

5. Ouzouni S, Kouidi E, Sioulis A, Grekas D, Deligiannis A. Effects of intradialytic exercise training on health-related quality of life indices in haemodialysis patients. Clin Rehabil. 2009; 23(1):53-63. [PubMed: 19114437]

6. Borg GA. Psychophysical bases of perceived exertion. Med Sci Sports Exerc. 1982; 14(5):377-381. [PubMed: 7154893]

7. Nelson ME, Rejeski WJ, Blair SN, et al. Physical activity and public health in older adults: recommendation from the American College of Sports Medicine and the American Heart Association. Med Sci Sports Exerc. 2007; 39(8):1435-1445. [PubMed: 17762378] 